\title{
Ageing Phenomena in La-Sr Manganites with Divalent Substituents for Manganese
}

\author{
D. Merkulov ${ }^{a, *}$, A. BAdelin ${ }^{a}$, S. Estemirova $^{b}$ And V. KarpasyuK ${ }^{a}$ \\ ${ }^{a}$ Astrakhan State University, Tatishchev str. 20a, 414056 Astrakhan, Russia \\ ${ }^{b}$ Institute for Metallurgy, UB Russian Academy of Sciences, Amundsen str. 101, 620016 Yekaterinburg, Russia
}

\begin{abstract}
Variations of electromagnetic and structural characteristics of $\mathrm{La}_{1-c+x} \mathrm{Sr}_{c-x} \mathrm{Mn}_{1-x} \mathrm{Me}_{x} \mathrm{O}_{3+\gamma}$ manganites $(\mathrm{Me}=\mathrm{Zn}, \mathrm{Ni})$ during storage time up to 36000 hours at room temperature and after frequentative thermal cycling in the 300-573 K range were investigated. Changes of magnetization of all samples were within the error of measurement. In most cases Curie point $\left(T_{\mathrm{C}}\right)$ showed irregular variations within the range of $20 \%$, while zinc-substituted manganites with relatively high values of "c" exhibited some trend of $T_{\mathrm{C}}$ rise. The resistance of all samples increased during storage period. The cell volume of single-phase manganites decreased over time, that may indicates an increase in oxygen content. However, the sample with the highest $\mathrm{Ni}$ content $(x=0.125)$ at $c=0.19$ suffered phase transition "rhombohedral-orthorhombic structures", which cannot be explained by the oxygen absorption. Probably, this effect was due to the rearrangement of the ions and vacancies between crystal sublattices of manganite.
\end{abstract}

DOI: 10.12693/APhysPolA.133.529

PACS/topics: 75.30.-m, 75.47.-m, 75.47.Lx, 81.70.--q

\section{Introduction}

Manganites exhibiting colossal magnetoresistance, giant magnetostriction and electrical switching properties are of interested as perspective materials for electronics [1-3]. Considering the technical application of manganites it is necessary to keep in mind that one of the major problems with electronic instrumentation is to provide a high level of the stability of functional parameters. Well studied phenomena of the changes in oxide materials properties with the time are, for example, disaccommodation and structural ageing in ferrites [4], drift of spinel manganite thermistors parameters [5]. However, despite the large number of developments and studies of perovskite-like manganites, the ageing processes in these materials are not still fully understood. Available information is mainly devoted to nanocompounds [6] and thin films [7], while data concerning bulk ceramic manganites are meager.

Since manganites, as well as ferrites, are oxide phases of variable composition containing ions of variable valency, great number of point defects, dislocations, and interacting with the surrounding atmosphere, there are common mechanisms and regularities of ageing processes in these groups of materials related to the thermodynamics and kinetics of solid-phase reactions [8-10]. General cause of the ageing is the lack of a true thermodynamic equilibrium under specified conditions. Thus, manganites cooled after high-temperature sintering are in unstable condition that gives rise to the transition into energetically more favorable state. Ageing mechanisms in

*corresponding author; e-mail: merkul_d@mail.ru considered materials are very diverse: exchange of oxygen with the ambient atmosphere; changes in valence and spin states of the ions; redistribution of cations and vacancies on the sublattices and in the volume of crystals; decomposition of solid solutions; relaxation of mechanical stresses, etc. Among these mechanisms there are diffusive and non-diffusive processes.

We have investigated structural, magnetic and electrical characteristics of ceramic manganites of the systems $\mathrm{La}_{1-c+x} \mathrm{Sr}_{c-x} \mathrm{Mn}_{1-x} \mathrm{Me}_{x}^{2+} \mathrm{O}_{3+\gamma}\left(\mathrm{Me}^{2+}=\mathrm{Zn}^{2+}, \mathrm{Ni}^{2+}\right)$ after single heat treatment, after thermal-cycling, as well as after prolonged storage in normal conditions with periodic measuring of the parameters. In the adduced chemical formula of compositions the sum of the contents of $\mathrm{Sr}^{2+}$ and $\mathrm{Me}^{2+}$ divalent ions is equal to the index $c$ which corresponds to the concentration of $\mathrm{Mn}^{4+}$ for stoichiometric $(\gamma=0)$ manganites. The values of $c$ were chosen near "orthorhombic-rhombohedral structure" boundary $(c=0.175)$ on the phase diagram of the $\mathrm{La}_{1-c}^{3+} \mathrm{Sr}_{c}^{2+} \mathrm{Mn}_{1-c}^{3+} \mathrm{Mn}_{c}^{4+} \mathrm{O}_{3}$ system [1].

\section{Experimental}

The experiments were performed on polycrystalline samples synthesized by traditional ceramic processing. The starting components (dried $\mathrm{La}_{2} \mathrm{O}_{3}, \mathrm{SrCO}_{3}, \mathrm{MnO}_{2}$, $\mathrm{ZnO}, \mathrm{NiO}$ powders) were mixed in stoichiometric proportions and ground in a ball mill with addition of ethanol. Pellets compacted of the obtained mixture were then preliminarily burned at $1273 \mathrm{~K}$ for $4 \mathrm{~h}$. This operation was followed by grinding, introducing a binder (an aqueous solution of polyvinyl alcohol), pressing the samples, and burning out the binder. The final sintering step was performed at $1473 \mathrm{~K}$ for $10 \mathrm{~h}$, and the samples were cooled together with the furnace. To determine the effect of thermal ageing on the properties of manganites 
two kinds of heat treatmen of initial (sintered) samples in air at different conditions were carried out: annealing at $873 \mathrm{~K}$ for 10 hours; the series of five consecutive annealings at $573 \mathrm{~K}$ for 6 hours each, followed by cooling and measurements of the parameters of samples. During long-term (up to 50 months) storage of initial samples at room temperature in air determination of the properties of manganites were carried in certain periods of time.

Phase composition and cell parameters were determined by powder X-ray diffraction at room temperature (diffractometer Shimadzu XRD-7000, $\mathrm{Cu} K_{\alpha}$ radiation). The magnetization per mass unit $(\sigma)$ was measured in magnetic field of $5.6 \mathrm{kOe}$. Measurements of dc electrical resistivity $(R)$ were made using copper electrodes sputter-deposited onto opposite planes of pellets (thickness of about $4 \mathrm{~mm}$ ). The temperature dependence of magnetic permeability $(\mu(T))$ was measured by the induction method at a frequency of $98.6 \mathrm{kHz}$, and Curie point $\left(T_{\mathrm{C}}\right)$ was determined as the temperature corresponding to the maximum of $|\mathrm{d} \mu / \mathrm{d} T|$.

\section{Results and discussion}

The data on the changes of magnetic parameters of manganites $\mathrm{La}_{0.81+x} \mathrm{Sr}_{0.19-x} \mathrm{Mn}_{1-x} \mathrm{Me}_{x} \mathrm{O}_{3+\gamma}(c=0.19)$ after single heat treatment at $873 \mathrm{~K}$ show that magnetization of all samples varies within the limits of measurement errors, as well as $T_{\mathrm{C}}$ of Ni-substituted manganites. Zn-contained compositions reveal some decrease of $T_{\mathrm{C}}$ at small " $x$ " (from 189 to $181 \mathrm{~K}$ at $x=0.025$ ) and the rise from 169 to $180 \mathrm{~K}$ at $x=0.125$.

Variations of magnetic parameters in the frequentative thermal cycling process are presented on the Fig. 1a,b. Similar to the previous case, magnetization fluctuations are within the error of measurement, $T_{\mathrm{C}}$ of $\mathrm{Ni}$ compositions remains practically unchanged, and Curie point of the compounds with zinc exhibits a weak rising tendency.

Analysis of the magnetic parameters values measured at certain intervals of time after beginning of the storage at room temperature permitted establishing the following regularities: magnetization of all samples does not change within measurement accuracy; $T_{\mathrm{C}}$ of the majority of the samples with small $c(c=0.15,0.17)$ after fluctuations in the range of $20 \%$ return roughly to initial values, while in compositions with $c=0.19, x=0.025$ and 0.125 Curie rises from 189 to $207 \mathrm{~K}$ and from 169 to $191 \mathrm{~K}$ in Zn-substituted manganites, as well as in Nicontained compositions $T_{\mathrm{C}}$ increases from 279 to $289 \mathrm{~K}$ and from 180 to $193 \mathrm{~K}$, correspondingly.

Figure 2 illustrates temperature dependences of the resistivity of Zn- and Ni-substituted manganites measured in initial state and in 16 months. The resistance of all aged samples increases.

Comparison of the curves on Fig. 2b shows that ageing leads to decrease of the "metal-semiconductor" transition temperature in Ni-substituted manganites.

Space group, unit cell volume (v) of manganites, and the increment of non-stoichiometry index $(\Delta \gamma)$ after 50

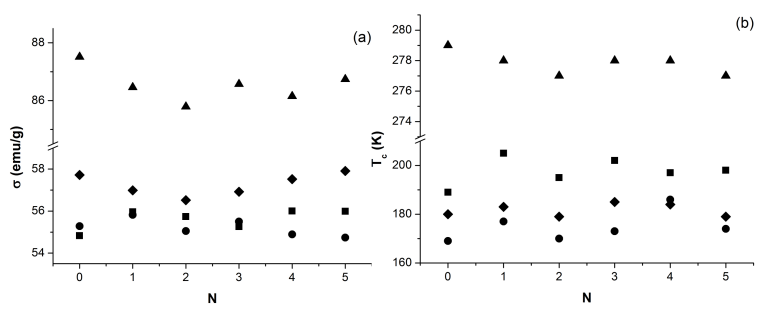

Fig. 1. Magnetization (a) and Curie point (b) of manganites $\mathrm{La}_{0.81+x} \mathrm{Sr}_{0.19-x} \mathrm{Mn}_{1-x} \mathrm{Me}_{x} \mathrm{O}_{3+\gamma}$ : $-\mathrm{Me}=\mathrm{Zn}$, $x=0.025 ; \bullet-\mathrm{Me}=\mathrm{Zn}, x=0.125 ; \boldsymbol{\Delta}-\mathrm{Me}=\mathrm{Ni}$, $x=0.025 ;-\mathrm{Me}=\mathrm{Ni}, x=0.125 ;$ the values of $\mathrm{N}$ denote the numbers of cycles $(N=0$ corresponds to the initial sample).
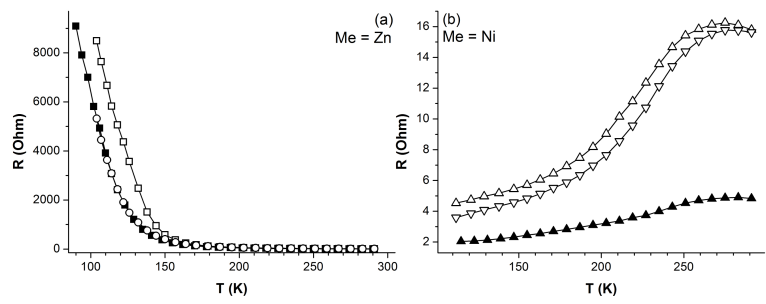

Fig. 2. Temperature dependencies of the resistivity of manganites $\mathrm{La}_{0.835} \mathrm{Sr}_{0.165} \mathrm{Mn}_{0.975} \mathrm{Me}_{0.025} \mathrm{O}_{3+\gamma}$ at initial state (black symbols) and after 16 months of storage (light symbols): $\mathbf{\square}, \square, \mathbf{\Delta}, \triangle-$ in the absence of magnetic field; $\circ, \nabla-$ at magnetic field.

months of storage are presented in Table I. The $\Delta \gamma$ values have been calculated from corresponding data on $\mathrm{v}$ decrement using the approach developed in [11].

TABLE I

Structural and non-stoichiometry characteristics of manganites $\mathrm{La}_{0.81+x} \mathrm{Sr}_{0.19-x} \mathrm{Mn}_{1-x} \mathrm{Me}_{x} \mathrm{O}_{3+\gamma}$.

\begin{tabular}{c|c|c|c|c}
\hline \hline \multicolumn{2}{c|}{$\begin{array}{c}\text { Chemical } \\
\text { composition }\end{array}$} & \multicolumn{2}{c|}{ Space group; $v\left[\AA^{3}\right]$} & \multirow{2}{*}{$\Delta \gamma, \gamma$} \\
\hline $\mathrm{Me}$ & $x$ & initial sample & aged sample & \\
\hline \multirow{2}{*}{$\mathrm{Zn}$} & 0.025 & $R \overline{3 c} ; 58.65$ & $R \overline{3 c} ; 58.63$ & 0.002 \\
\cline { 2 - 4 } & 0.125 & Pnma; 59.45 & Pnma; 59.42 & 0.003 \\
\hline \multirow{2}{*}{$\mathrm{Ni}$} & 0.025 & $R \overline{3 c} ; 58.96$ & $R \overline{3 c} ; 58.85$ & 0.010 \\
\cline { 2 - 4 } & 0.125 & $R \overline{3 c} ; 58.90$ & Pnma; 59.09 & $\gamma=0.018$
\end{tabular}

All manganites with $c=0.19, x=0.025$ in initial state and after ageing are rhombohedral. Samples with high amount of $\mathrm{Zn}(x=0.125)$ have orthorhombic structure. Unit cell volume of above-mentioned compositions by the end of the storage period decreases, that may be associated with increasing oxygen content (Table I). The increase of $\gamma$ is consistent with thermodynamical notions [8].

Oxidation process results in increase of the concentration of $\mathrm{Mn}^{4+}$ ions bonded with $\mathrm{Mn}^{3+}$ by double exchange interaction that leads to higher ferromagnetic characteristics and conductivity. On the contrary, the decrease of 
magnetic moment of the manganese ions and dilution of Mn sublattice by cation vacancies aggravate electromagnetic parameters.

Of great interest is the phenomenon of phase conversion from rhombohedral to orthorhombic structure in Nicontained compositions with $x=0.125$ after long-term storage. Such conversion may not be directly related to the oxygen absorption, because excess of oxygen content promotes the existence of rhombohedral phase [10]. Actually, after annealing under conditions resulting in stoichiometric oxygen content $[8,10,11]$, this manganite became orthorhombic with $v=59.29 \AA^{3}$. The result obtained made it possible to find index $\gamma=0.018$ for aged manganite (Table I). Phenomenon under consideration can be due to the transition of $\mathrm{Ni}^{2+}$ ions from octahedral sublattice for vacancies in the sublattice of lanthanum-strontium. The possibility of such rearrangement of cations and vacancies was considered in $[8,9]$. As a result tolerance factor [1] of manganite decreases, and $T_{\mathrm{C}}$ rises. Similar effects can occur in the compositions containing zinc.

\section{Conclusions}

On the whole, it is possible to conclude that thermal ageing and ageing of manganites during prolonged storage under normal conditions does not lead to significant changes in their magnetic properties. Variations of magnetization are within measurement error, and fluctuations of Curie poin are in the range of $20 \%$ with some trend of $T_{\mathrm{C}}$ rise.

Ageing processes in manganites can be ascribed to the oxidation processes and to the rearrangement of the substituting ions and vacancies between crystal sublattices of manganite.

Great changes of resistivity of the samples with sputter-deposited electrodes can be mainly associated with degradation of the contact zones under the oxidation of copper by the oxygen from manganite.

\section{References}

[1] E. Dagotto, T. Hotta, A. Moreo, Physics reports 344, 1 (2001).

[2] L.I. Koroleva, D.M. Zashchirinski, T.M. Khapaeva, L.I. Gurski, N.A. Kalanda, V.M. Trukhan, R. Szymczak, B. Krzumanska, Phys. Solid State 52, 96 (2010).

[3] V.K. Karpasyuk, A.G. Badelin, A.M. Smirnov, V.V. Sorokin, A. Evseeva, E. Doyutova, A.A. Shchepetkin, J. Phys.: Conf. Ser. 200, 052026 (2010).

[4] S. Krupićka, Physik der ferrite und der verwandten magnetischen oxide Academia, Prag 1973.

[5] Dao-lai Fang, Cui-hong Zheng, Chu-sheng Chen, A.J.A. Winnubst, J. Electroceram. 22, 421 (2009).

[6] A.I. Rykova, A.V. Terekhov, A.S. Cherny, E.N. Khatsko, A.V. Yeremenko, A. Zaleski, Low Temp. Phys. 38, 529 (2012)

[7] L. Žurauskaitė, S. Balevičius, N. Žurauskienè, S. Keršulis, V. Stankevič, C. Simkevičius, J. Novickij, S. Tolvaišienè, Lithuanian J. Phys. 52, 224 (2012).

[8] J. Mizusaki, N. Mori, H. Takai, Y. Yonemura, H. Minamiue, H. Tagawa, M. Dokiya, H. Inaba, K. Naraya, T. Sasamoto, T. Hashimoto, Solid State Ionics $\mathbf{1 2 9}$ $163(2000)$.

[9] Z.R. Musaeva, A.G. Badelin, A.M. Smirnov, V.K. Karpasyuk, V.I. Ponomarev, A.A. Shchepetkin, Bul. Rus. Acad. Sci. Phys. 74, 1462 (2010).

[10] A.G. Badelin, V.K. Karpasyuk, A.M. Smirnov, A.V. Evseeva, E.P. Firsova, S.Kh. Estemirova, Bul. Rus. Acad. Sci. Phys. 78, 100 (2014).

[11] D. Merkulov, A. Badelin, S. Estemirova, V. Karpasyuk, Acta Physica Polonica A 127, $248(2015)$. 